\title{
The interplay between learner beliefs and foreign language anxiety: insights from the Turkish EFL context
}

Article

Accepted Version

Aslan, E. and Thompson, A. S. (2021) The interplay between learner beliefs and foreign language anxiety: insights from the Turkish EFL context. Language Learning Journal. ISSN 17532167 doi: https://doi.org/10.1080/09571736.2018.1540649 Available at https://centaur.reading.ac.uk/80363/

It is advisable to refer to the publisher's version if you intend to cite from the work. See Guidance on citing.

To link to this article DOI: http://dx.doi.org/10.1080/09571736.2018.1540649

Publisher: Taylor \& Francis

All outputs in CentAUR are protected by Intellectual Property Rights law, including copyright law. Copyright and IPR is retained by the creators or other copyright holders. Terms and conditions for use of this material are defined in the End User Agreement.

www.reading.ac.uk/centaur 
Central Archive at the University of Reading

Reading's research outputs online 


\title{
The interplay between learner beliefs and foreign language anxiety: Insights from the Turkish EFL context
}

\begin{abstract}
Foreign language learning in classroom settings has long been found to be associated with anxiety (Horwitz, 1986). Though it is known that sources of foreign language anxiety are varied (Young, 1991), whether anxiety is related to learners' inherent beliefs about language learning is understudied. To this end, the present study examines the possible relationship between learner beliefs and language anxiety in the under-researched Turkish EFL context. A population of university-level Turkish EFL learners ( $\mathrm{n}=153)$ completed the Beliefs about Language Learning Inventory (BALLI) and the Foreign Language Classroom Anxiety scale (FLCAS). The underlying constructs in both instruments were explored using an Exploratory Factor Analysis (EFA). A series of Pearson Product-Moment Correlation Coefficient (PPMCC) tests were performed on the factor scores from both instruments. The findings revealed that fear of ambiguity was positively linked to classroom performance anxiety and negative feelings towards English. In addition, the more confident learners feel themselves using English, the more desire they seem to have to interact with native speakers. Overall, positive beliefs about language learning may be helpful in reducing anxiety and boosting confidence in language learning. These findings not only enhance our understanding of the complex psychology of language learning but also have important implications for instructed EFL/ESL settings.
\end{abstract}

Key words: individual differences, second language acquisition, learner beliefs, foreign language anxiety, Turkish EFL

\section{Introduction}


Foreign language learning is known to be affected by a number of individual differences (IDs), such as aptitude, motivation, beliefs, anxiety, and personality, among others. For the past three decades, a body of research has examined how IDs impact foreign language learning processes in different contexts. For example, Thompson (2013) found evidence that language learners' previous language learning experiences and their language aptitude were interrelated. Regarding language learning motivation, even skillful learners would not be able to achieve long-term second language (L2) learning goals without sufficient motivation (Dörnyei, 2005), and that visualization and imagery are crucial in creating a strong ideal L2 self, thereby enhancing motivation (Dörnyei 2009). As much as aptitude and motivation, learner beliefs about language learning and foreign language anxiety in the classroom, which are central to the present study, also received scholarly attention. Even though several studies identified important constructs regarding learners' beliefs about language learning (e.g. Loewen, Li, Fei, Thompson, Nakatsukasa, Ahn, \& Chen (2009), Oz (2007), Thompson \& Aslan, 2015), little research has been conducted regarding the relationship between learner beliefs and anxiety. However, Horwitz (1987) contended that factors leading to foreign language anxiety might be accounted for in part by the beliefs learners construct about language learning, making the relationship between language learning beliefs and anxiety an essential avenue of inquiry to pursue. Therefore, the present study aims to contribute to the existing literature of IDs by exploring whether learner beliefs about language learning are linked to foreign language classroom anxiety in the Turkish EFL context.

\section{Review of literature}

\section{Learner beliefs about language learning}

Learner beliefs about language learning result from a variety of sources, such as previous language learning experiences, cultural background, and personality traits (Ellis, 2008). In other 
words, learner beliefs refer to how learners position themselves as language learners in a given learning context, and their beliefs affect the way they control their own learning. Additionally, learner beliefs include attitudes shaped in a particular learning setting towards language instruction, including formal and informal language institutions, the teachers, and other learners (Thompson \& Aslan, 2015). Equally influential in the construction of learner beliefs is the target community which includes the people of the target foreign language, and the perceptions of learners' about the target culture.

To measure the language learning beliefs of learners, Horwitz (1988) created the Beliefs about Language Learning Inventory (BALLI) questionnaire. In the US context, Loewen et al. (2009) investigated the underlying constructs of learner beliefs about grammar instruction and error correction. They identified six factors, namely "efficacy of grammar," "negative attitude to error correction," "priority of communication," "importance of grammar," "importance of grammatical accuracy," and "negative attitudes to grammar instruction." Since the BALLI was initially based on US foreign language context, it was not a complete inventory of learner beliefs in general (Horwitz, 1988). Consequently, it has been modified and adapted to a variety of foreign language learning contexts. For instance, Ariogul, Ünal, and Onursal (2009) compared English, German and French language learners' beliefs in the Turkish context. In a longitudinal study, Kern (1995) investigated the beliefs of university students of French at the beginning of their first and at the end of their second semester of studies using the BALLI. In the context of Lebanon, Lebanese university students believed English to be an easy language to learn, whereas they found French to be a difficult language (Diab, 2006). Similar to the results of Diab (2006) with regard to French, Nikitina and Furuoka (2007) found that most learners in the multilingual context of Malaysia believed that Russian is hard to understand, and its grammar is difficult. As can be seen, research in this area has enhanced our understanding or the diverse beliefs learners 
have towards different languages and how these beliefs might impact the language learning processes.

Learner beliefs about language learning have been investigated through exploratory factor analyses in a number of studies. For example, Mori (1999) investigated the relationships between general epistemological beliefs and foreign language learning beliefs. The five epistemological belief dimensions which are concerned with the nature of knowledge and knowledge acquisition were "the structure of knowledge" (simple knowledge), "the attainability of knowledge" (attainability of the truth), "the source of knowledge" (dependence on authority), "the controllability of the ability to acquire knowledge" (innate ability), and "the speed of knowledge acquisition" (quick learning). On the contrary, the language learning belief dimensions were related to different aspects of foreign language learning, such as perception of the difficulty (Kanji is difficult, Japanese is easy), the effectiveness of approaches to or strategies for language learning" (risk taking, analytic approach, avoid ambiguity), and "the source of linguistic knowledge [reliance on first language (L1)]. In the secondary education EFL context of Turkey, Öz (2007) identified five factors about language learning beliefs. These were "beliefs about social interaction and learning spoken English," "beliefs about structural language learning," "beliefs about quality and adequacy of EFL instruction," "beliefs about difficulty and perceived value of language learning," and "beliefs about foreign language aptitude." Translation, vocabulary and grammar were found to be important parts of language learning. In a similar study, Thompson and Aslan (2015) found that Turkish learners also fear ambiguity to some extent in the guise of making mistakes, correct language use, the importance of mastering the grammar of a language, speaking with an excellent pronunciation and fear with speaking English with others. 
As these studies indicate, learner beliefs constitute an important part of the language learning process and factors affecting learners' beliefs require more scholarly attention. To this end, the present study set out to investigate whether beliefs about language learning might be related to foreign language anxiety, another important ID in the second language acquisition (SLA) literature.

\section{Foreign language anxiety}

According to Horwitz, Horwitz, and Cope (1986), foreign language anxiety stems from underdeveloped communicative abilities in L2, which usually leads to fear of communication, self-consciousness, or silence. The measure of anxiety used in much of the research on foreign language anxiety is the Foreign Language Classroom Anxiety Scale (FLCAS) created by Horwitz (1988). Foreign language anxiety is also related to the concept of tolerance of ambiguity (TA) which "refers to the way an individual (or group) perceives and processes information about ambiguous situations when confronted by an array of unfamiliar, complex, or incongruent cues" (Furnham \& Ribchester 1995, p. 179). Originally used in different fields of psychology to understand social groups, discourse systems, and individuals (Furnham, 1994), tolerance of ambiguity is now used in second language acquisition to understand complex learner behaviours and language learning processes. According to Rubin (2008), the process of language learning can help learners become more comfortable with uncertainty and ambiguity. Indeed, several scholars have noted benefits of tolerance of ambiguity in language learning. Oxford and Ehrman (1992) claim that tolerance of ambiguity predicts L2 learners' learning strategies, particularly in learners' ability to make decisions. Ely (1995) argues that tolerance of ambiguity can facilitate learning if learners are made aware of linguistics differences through inquiry and analysis.

Inquiring about English anxiety of Korean EFL learners, Thompson and Lee (2013, 2014), found 'fear of ambiguity' as one of the factors leading to foreign language anxiety in the 
classroom. Thompson and Lee (2013) also found a significant difference in the low and high English proficiency, with the low-proficiency learners having greater English anxiety. In a similar study in the Turkish EFL context, Thompson and Khawaja (2015) found that "English class performance anxiety" and "fear of ambiguity in English" factors were closely related to one another. Additionally, they suggested that tolerance of ambiguity can also be related to varying levels of foreign language anxiety.

Negative correlations between anxiety and performance have been found in several studies (e.g. Aida, 1994 and Horwitz, 1986). Specifically, speaking publicly in the L2 was found to be particularly anxiety inducing for many learners, relatively more than in other aspects of language learning (Horwitz, 1995). Young (1991) identified six potential sources of foreign language anxiety: "personal and interpersonal issues," "instructor-learner interactions," “classroom procedures," "language testing," "instructor beliefs about language learning," and “learner beliefs about language learning.” According to Horwitz (1987), learner beliefs are the most important to consider when accounting for foreign language anxiety. Furthermore, the impact of beliefs on learners' experience of anxiety has been emphasized in cognitive and educational psychology theory and research (Cheng, 2001). Investigating how second language anxiety was related to two different kinds of learner beliefs, specifically self-efficacy and giftedness in second language learning, Cheng (2001) found that Taiwanese students' level of anxiety about English class was positively and moderately correlated with giftedness belief, but was negatively and strongly correlated with their belief about English self-efficacy. More specifically, learners with higher levels of language class anxiety were more inclined to believe that the ability to learn a foreign language well is a gift, and their self-assessment of language abilities was low. Additionally, learners with less confidence in their English abilities believed more strongly in giftedness. As previously mentioned, since learner beliefs and foreign language 
anxiety are multidimensional constructs, the possible relationships between the two need further empirical attention.

\section{The study}

The purpose of the present study which is a part of a larger project focusing on various IDs in the Turkish EFL context is to explore the relationships between the underlying factors of Turkish EFL learners' beliefs about language learning and foreign language anxiety. Identifying the possible connections between these two constructs will provide important insights into instructed adult second/foreign language learning; as Horwitz (1987) suggests, there is likely a relationship between language learning anxiety and beliefs about language learning. In light of this purpose, the present study investigates the following research question:

- What is the relationship between the underlying factors in the language learning beliefs and foreign language anxiety of Turkish EFL learners?

\section{Participants}

A total of 153 Turkish EFL learners enrolled in different universities in Turkey participated in this study. The majority of the participants reported Turkish as their first language, although there were a small number of participants who reported other languages as their first language, such as Kurdish. The participants were adult EFL learners, approximately $70 \%$ of whom were between 18 and 22 years old; the other $30 \%$ were older than 22 . With regard to language learning experiences, all participants had studied English, and many of the participants had previously studied another foreign language of foreign languages. After English, German was the most commonly studied second foreign language, followed by other foreign languages, such as French, Spanish, Arabic, Russian, Italian, and Korean.

\section{Data collection procedures}


All participants completed a series of surveys, including a background questionnaire and the BALLI and FLCAS questionnaires. A modified version of the BALLI was used in the present study. In order to adapt it to the Turkish EFL context, two items from the original BALLI were removed. These items were "The language I am trying to learn is structured in the same way as English" and "If I speak this language very well, I will have many opportunities to use it." Four questions were added to the questionnaire of this study: "I would like to learn English so that I can better understand people who speak English as a native language," "The most important part of learning English is learning how to translate from English to the L1," "I want to learn to speak English well," and "Language learning involves a lot of memorization." The wording was also revised to update certain concepts (i.e. language labs) and to make the questionnaire context-specific (i.e. replacing "the foreign language" with "English"). A total of 35 BALLI items were included in the analysis, while the FLCAS consisted of 33 items. The items in each survey were based on a Likert scale, 1 being "strongly disagree" and 6 being "strongly agree."

Participants were recruited via an email sent to English language teachers working in various universities in Turkey. In the email, there was a brief description of the study along with a link to SurveyMonkey.com where the survey had been created. The teachers were asked to share the link to the surveys with their students. Since the participants had varying levels of English proficiency, all of the questionnaire items were presented both in English and in Turkish. Participation was voluntary with no incentive offered to the participants, and any Turkish student who had studied or was studying English was eligible to participate in the study. Data were collected for a period of one year before the analysis began.

\section{Data analysis}


The statistical tests used in this study were Exploratory Factor Analysis (EFA) and Pearson Product-Moment Correlation Coefficient (PPMCC). The tests were performed via SPSS version 22. To answer the research question of the current study, based on the factors that emerged from the EFAs, PPMCC tests were performed on the factor scores in order to explore the relationships between BALLI and FLCAS factors. In what follows is a summary of the EFAs conducted on the beliefs and anxiety responses.

\section{Results}

\section{The BALLI factor scores}

The EFA performed on the BALLI had internal consistency of .854, measured by Cronbach's alpha. The KMO value was .785, indicating that the sample size was adequate. The extraction method used was the Maximum Likelihood and the rotation method was oblique direct oblimin. The items which loaded at .3 or greater onto a factor were included, and only the factor loadings that had an eigenvalue greater than 1 were retained, resulting in a final five-factor solution (see the scree plot in Figure 1). Table 1 presents the resulting factors with the items that loaded onto them:

Table 1. The BALLI Factors

Factor 1: Desire/necessity for learning English well

32. I want to learn to speak English well.

5. I believe that I will ultimately learn to speak English very well.

30. If I learn English very well, I will have better opportunities for a good job.

Factor 2: Importance of translation in language learning

29. The most important part of learning English is learning how to translate from English to the L1. 28. The most important part of learning English is learning how to translate from the L1 to English 
Factor 3: Confidence in English and desire to interact with native speakers and culture

13. I enjoy practicing English with people who speak English as a native language.

16. I have a special ability for learning foreign languages.

24. I would like to learn English so that I can better understand people who speak English as a native language.

31. People who speak more than one language are very intelligent.

33. I would like to get to know people who speak English as a native language.

8. It is necessary to know about English speaking cultures in order to speak English well.

Factor 4: Linguistic accuracy

22. If beginning students are allowed to make mistakes in English in the beginning, it will be hard to speak correctly later on.

9. You should not say anything in English until you can say it correctly.

21. I feel timid speaking English with other people.

7. It is important to speak English with an excellent pronunciation.

23. The most important part of learning a foreign language is learning the grammar.

Factor 5: Situation for English learning

3. Some languages are easier to learn than others.

1. It is easier for children than adults to learn a foreign language.

12. It is better to learn English in an English-speaking country.

2. Some people are born with a special ability for learning foreign languages.

10. It's easier for someone who already speaks a foreign language to learn another one. 


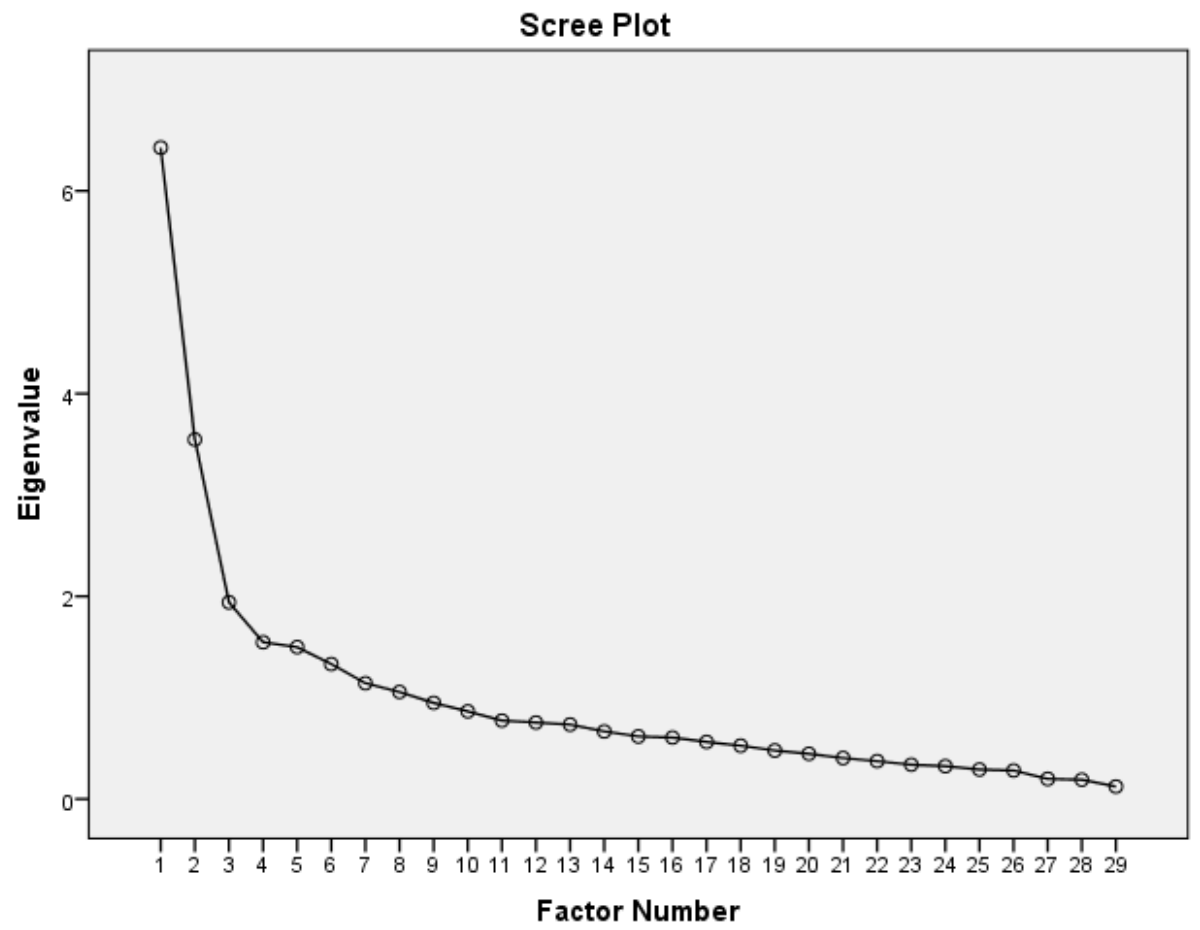

Figure 1. Scree plot for BALLI factors

The EFA performed on the BALLI scores revealed five factors accounting for Turkish EFL learners' language learning beliefs. The five-factor solution which included 21 items accounted for the $51.58 \%$ of the total variance. The first factor (F1), "Desire/necessity for learning English well," had three items and accounted for $22.16 \%$ of the total variance with a Cronbach's alpha of .73. The second factor (F2), "Importance of translation in language learning," contained two items and explained $12.23 \%$ of the total variance with a Cronbach's alpha of .89. The third factor (F3), "Confidence in English and desire to interact with native speakers and culture," had six items loaded and accounted for $6.69 \%$ of the total variance with a Cronbach's alpha of .82. The fourth factor (F4) with five items was named "Linguistic accuracy" and explained 5.33\% of the total variance with a Cronbach's alpha of .68. The fifth factor (F5), "Situation for English learning," had five items and explained 5.16\% of the variance with a Cronbach's alpha of .73. 
Following the same procedures in the BALLI EFA, the EFA conducted on the FLCAS items resulted in a four-factor structure with a Cronbach's alpha of .901 , accounting for $63.60 \%$ of the total variance. Figure 2 shows the factor loadings in a scree plot. The Cronbach's alpha for each factor was calculated $(\mathrm{F} 1=.96, \mathrm{~F} 2=.82, \mathrm{~F} 3=.85$, and $\mathrm{F} 4=.88) . \mathrm{F} 1$, "English class performance anxiety," explained $50.28 \%$ of the variance contained 16 items dealing with various anxiety-inducing situations that not only pertain to using English in the classroom but also involve the interaction with teachers and peers. F2, accounting for $6.71 \%$ of the variance, is named "Confidence with English," due to the loading of seven items dealing with comfort and confidence in using English in the classroom and other speakers. F3, "Negative feelings towards the English language," explained $3.98 \%$ of the variance with six items which indicate unwillingness or reluctance to study English. It should be noted here that item 5 in F3 'It wouldn't bother me at all to take more English classes' had a negative factor loading, and was, thus, reverse coded. Therefore, the negative loading indicates that the learners would indeed be bothered by more English classes. Finally, F4, "Fear of ambiguity in English," accounted for $2.63 \%$ of the variance with four items indicating feelings of uncertainty associated with English use or classroom instruction and communication. Table 2 includes the FCLAS factor names with the items that loaded onto them. 


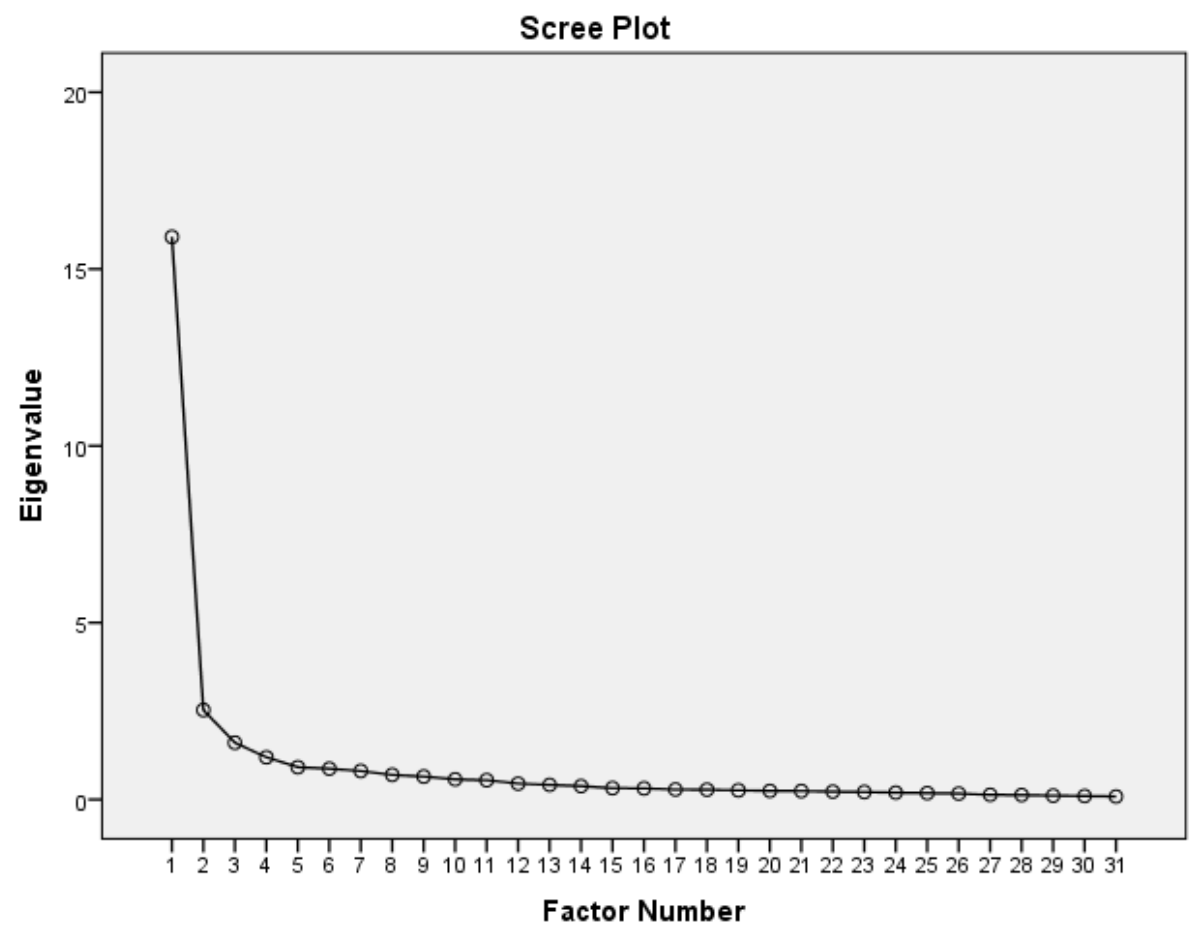

Figure 2. Scree plot for FLCAS factor loadings

Table 2. The FLCAS Factors

Factor 1: English class performance anxiety

23. I always feel that the other students speak English better than I do.

19. I am afraid that my English teacher is ready to correct every mistake I make.

31. I am afraid the other students will laugh at me when I speak English.

24. I feel very self-conscious about speaking English in front of other students.

12. In English class, I can get so nervous that I forget things I know.

20. I can feel my heart pounding when I'm going to be called on in English class.

7. I keep thinking that other students are better at English than I am.

21. The more I study for an English test, the more confused I get.

26. I feel more tense and nervous in my English class than in my other classes.

13. It embarrasses me to volunteer answers in my English class.

16. Even if I am well prepared for English class, I feel anxious about it.

27. I get nervous and confused when I am speaking in my English class.

25 . English class moves so quickly that I feel worried about getting left behind.

33. I get nervous when the English teacher asks questions which I haven't prepared in advance.

3. I tremble when I know that I'm going to be called on in English class.

15. I get upset when I don't understand what the teacher is correcting. 
Factor 2: Confidence with English

18. I feel confident when I speak in my English class.

28. When I'm on my way to English class, I feel very sure and relaxed.

32. I would probably feel comfortable around native speakers of English.

2. I don't worry about making mistakes in English class.

8. I am usually at ease during tests during my English class.

14. I would not be nervous speaking English with native speakers.

11. I don't understand why some people get so upset over English classes.

Factor 3: Negative feelings towards English

30. I feel overwhelmed by the number of rules you have to learn to speak English.

17. I often feel like not going to my English class.

6. During English class, I find myself thinking about things that have nothing to do with the course.

5. It wouldn't bother me at all to take more English classes.

Factor 4: Fear of ambiguity

4. It frightens me when I don't understand what the teacher is saying in the English class

9. I start to panic when I have to speak without preparation in English class.

29. I get nervous when I don't understand every word the English teacher says.

1. I never feel quite sure of myself when I am speaking in my English class.

\section{Correlations between the BALLI and FLCAS factors}

The Pearson product-moment correlation coefficients between all the BALLI and FLCAS factors were computed to find out whether learner beliefs and anxiety factors were linked. As shown in Table 3, the five BALLI factors and the four FLCAS factors were for the most part significantly correlated, although the strength of the correlations varied between the variables. The results indicate that, of the 20 correlations between the BALLI and FLCAS factors, there are 14 that reached significance. This suggests that learner beliefs about language learning and foreign language anxiety are two interrelated constructs. The lack of significant correlations between 6 combinations indicates that some belief and anxiety factors have weaker correlations. 
The findings revealed that FLCAS-F2 "Confidence with English" did not significantly correlate with BALLI-F2 “Importance of translation in language learning.” This suggests that learners' beliefs about the importance of translating between Turkish and English are not associated with being confident (or not) in English. One possible interpretation here is that within this group of Turkish learners, translation does not appear to provoke particular levels of anxiety. Two anxiety factors, FLCAS-F1 "English class performance anxiety" and FLCAS-F4 "Fear of ambiguity" did not significantly correlate with BALLI-F3 "Confidence in English and desire to interact with native speakers and culture." While it might be expected that the beliefs about integrativeness in the target culture and willingness to communicate with its speakers could be associated with low levels of classroom performance anxiety and fear of ambiguity, this lack of correlation may be attributed to the fact that learners do not have to interact with native speakers in the classroom setting because both their peers and the teacher are generally L1 Turkish speakers. Therefore, their beliefs about interacting with native speakers do not pertain to the classroom setting and may not be associated with anxiety.. Finally, BALLI-F5 "Situation for learning English" did not significantly correlate with three anxiety factors. These were FLCAS-F1, FLCAS-F3, and FLCAS-F4. This finding suggests that beliefs about the effectiveness of the situations in which language learning takes place, such as study abroad or instructional environments, as well as the ease and difficulty of languages being learned are independent from performance anxiety, negative feelings towards English, and fear of ambiguity.

Table 3. Correlations between beliefs and anxiety factors 


\begin{tabular}{|c|c|c|c|c|c|}
\hline & $\begin{array}{l}\text { BALLI-F1 } \\
\text { Desire/ } \\
\text { necessity for } \\
\text { learning Eng. } \\
\text { well }\end{array}$ & $\begin{array}{l}\text { BALLI-F2 } \\
\text { Importance of } \\
\text { trans. in lang. } \\
\text { learn. }\end{array}$ & $\begin{array}{l}\text { BALLI-F3 } \\
\text { Conf. in Eng. } \\
\text { and desire to } \\
\text { interact with } \\
\text { nat. speak. } \\
\text { and cult. }\end{array}$ & $\begin{array}{c}\text { BALLI-F4 } \\
\text { Linguistic } \\
\text { accuracy }\end{array}$ & $\begin{array}{l}\text { BALLI-F5 } \\
\text { Situation for } \\
\text { English } \\
\text { learning }\end{array}$ \\
\hline $\begin{array}{l}\text { FLCAS-F1 } \\
\text { Eng. class } \\
\text { perf. anxiety }\end{array}$ & $-.20^{*}$ & $.24^{* *}$ & -.09 & $.54^{* *}$ & -.10 \\
\hline $\begin{array}{l}\text { FLCAS-F2 } \\
\text { Conf. with } \\
\text { Eng. }\end{array}$ & $.38^{* *}$ & -.14 & $.42^{* *}$ & $-.30^{* *}$ & $.16^{*}$ \\
\hline $\begin{array}{l}\text { FLCAS-F3 } \\
\text { Neg. feelings } \\
\text { towards Eng. }\end{array}$ & $-.50^{* *}$ & $.26^{* *}$ & $.35^{* *}$ & $.32^{* *}$ & -.14 \\
\hline $\begin{array}{l}\text { FLCAS-F4 } \\
\text { Fear of } \\
\text { ambiguity }\end{array}$ & $-.17^{*}$ & $.23^{* *}$ & -.14 & $.47^{* *}$ & -.03 \\
\hline
\end{tabular}

$* p<.05 * * p<.01$

As shown in Table 3, there are several interesting significant positive and negative correlations between some BALLI and FLCAS factors. Learners' beliefs about the necessity for learning English well (BALLI-F1) positively correlated $(r=.38)$ at a significant level with confidence with English (FLCAS-F2), meaning that the more confident learners are with learning English, the more strongly they believe in the importance of learning English well, or vice versa. This finding suggests that confidence and language learning desire may influence each other bidirectionally, meaning that mastering language skills may increase confidence in using those skills or learner confidence and autonomy may encourage learners to study English more effectively. Additionally, there was a significant negative correlation with BALLI-F1 and FLCAS-F1 $(r=-.20)$, suggesting that those who do not feel so strongly that learning English is a necessity experience greater performance anxiety due 
to a possible weaker foundation for motivation. . In other words, learners may be afraid to participate in class activities or use English in class when they don't believe that they need to learn English well. A significant negative correlation between BALLI-F1 and FLCAS-F3 $(r=-.50)$ suggests a link between negative feelings English. Similarly, though a weaker correlation, BALLI-F1 had a significant negative correlation with FLCAS-F4 ( $r=-.17)$, which suggests fear of ambiguity could be associated with weak beliefs about learning English well.

A set of positive significant correlations exist between BALLI-F2 "Importance of translation in language learning" and three of the FLCAS factors (FLCAS-F1 "English class performance anxiety", FLCAS-F3 "Negative feelings towards English," and FLCAS-F4 "Fear of ambiguity"). The significant positive correlation between BALLI-F2 and FLCAS-F1 $(r=.24)$ indicates that classroom performance anxiety may increase with learners' beliefs about the importance of translating language forms or sentences into their L1 during class activities. This interesting finding suggests that learners' belief that they need to translate brings an extra cognitive load, and therefore, may increase performance anxiety in the classroom. Similarly, the significant positive relationship between BALLI-F2 and FCLAS-F3 ( $r$ $=.26)$ shows that when beliefs about the importance of translation in language learning are strong, learners might have negative feelings towards English. Additionally, fear of ambiguity (FLCAS-F4) also positively correlated with BALLI-F2 $(r=.23)$, which suggests that strong beliefs about translation in language learning may induce more fear of ambiguity in the classroom, possibly resulting from the mismatches between the linguistic forms in Turkish and English. In other words, fear of ambiguity might be associated with a need for certainty and learners may be inclined to find one-to-one translations of linguistic forms of English and Turkish. For instance, the present perfect aspect of the verb in English (e.g., have/has + past participle) might increase Turkish learners' fear of ambiguity as there is no direct equivalent of it in Turkish. 
The findings indicate a significant positive relationship between BALLI-F3 "Confidence in English and desire to interact with native speakers and culture" and FLCAS-F2 "Confidence in English" $(r=.42)$. This relationship is not surprising in that when learners have a strong desire to interact with English-speaking people and cultures, they have higher confidence in the foreign language classroom. Another interesting significant positive relationship is between BALLI-F3 and FLCAS-F3 "Negative feelings towards English" $(r=.35)$. This finding suggests that the more negative feelings learners have towards the classroom setting, the more desire they have to interact with native speakers of English and learn about the target culture. In other words, when learners believe in the importance of interacting with native English speakers, they may not always enjoy classroom learning very much. More specifically, they may be bored with the classroom activities, such as traditional grammar-based "fill-in-the-blank" type of activities, and they may desire interaction outside the classroom context.

The BALLI-F4 "Linguistic accuracy" was found to significantly correlate (some positively and some negatively) with all of the FLCAS factors. The strongest correlation was found between BALLIF4 and FLCAS-F1 "English class performance anxiety" $(r=.54)$, indicating that when learners are believe in linguistic accuracy, such as having to produce correct grammatical forms different from the L1, accurately pronouncing words, or trying to avoid making mistakes, they are likely to experience performance anxiety. BALLI-F4 also significantly positively correlated with FLCAS-3 "Negative feelings towards English" $(r=.32)$ and FLCAS-4 "Fear of ambiguity" $(r=.47)$. These correlations indicate that learners' beliefs about accuracy in using language may increase their anxiety level in the classroom. The only FLCAS factor with which BALLI-F4 significantly negatively correlated was FLCAS-F2 "Confidence with English" $(r=-.30)$. This negative relationship suggests that when learners strongly believe that the language learning situation involves risk-taking, accuracy, and excellence, their confidence level in the classroom couldbe low. In other words, placing linguistic 
accuracy at the forefront of learning and communication in the classroom might potentially jeopardize learners' confidence level as linguistic accuracy could possibly evoke fear and/or intolerance of making mistakes due to the desire to use language correctly at all times.

Finally, BALLI-F5 "Situation for learning English" was found to correlate only with FLCASF2 $(r=.16)$, suggesting that beliefs about how and where to learn English may be influenced by learners' confidence with using English.

\section{Discussion and conclusion}

The findings of this study support the view that both learners' beliefs about language learning in general and foreign language anxiety consist of several constructs which interact with one another. The complexity and multidimensionality of learner beliefs and foreign language anxiety was documented through exploratory factor analyses in previous research (Mori, 1999; Thompson \& Aslan, 2015; Thompson \& Khawaja, 2015). The contribution of the present study is that it offers empirical evidence for the association between the underlying constructs of beliefs and anxiety in foreign language learning.In light of previous research, the significant moderate positive correlation found in the present study between confidence in English and beliefs about learning English well $(r=.38)$ supports Cheng's (2001) significant negative correlation between foreign language anxiety and beliefs about self-efficacy $(\mathrm{r}=-.68)$. These findings also resonate with those of Okay and Balcikanli (2017) who, specifically in the Turkish EFL context, found that self-confident learners do not usually feel anxious about using English., These findings have important implications for second language learners' performance in both instructional and non-instructional settings. Given that positive beliefs about language learning may reduce anxiety and boost confidence in language learning, the investigation of beliefs about second language competence could enable teachers and researchers to identify patterns and sources of second language anxiety and/or inaccurate beliefs about second 
language learning. Such information about language learners constitutes an important component of learner needs analysis in any language curriculum design project, particularly with respect to language teaching methodology and, material and activity development, to name a few.

The negative correlation between BALLI-F1 (desire/necessity to learn English well) and FLCAS-F3 (negative feelings towards English) $(r=-.54)$ in that negative feelings about the language classroom might result from the unwillingness to learn a foreign a language or lack of awareness of the importance of learning a foreign language. Therefore, in light of these conclusions, an important implication for second/foreign language teaching is that teachers should come up with different ways to provide a safe and supportive learning environment in which learners are convinced that knowing a language well enough to communicate with others does not require one to understand every single word that is heard or read. Doing so can lower learners' affective filters and adopt more positive feelings towards learning English. Additionally, research indicates that there is a strong association between language learners' motivation, and feelings about and attitudes toward the target language, culture and society, which impact learners' achievement levels in a second language (Dörnyei 2009). Therefore, learners' beliefs about language learning and their second language anxiety levels can better be understood within culturally-informed personal values and societal pressures with respect to language learning.

An important finding of the present study is the set of significant correlations found between fear of ambiguity and several beliefs and anxiety constructs. As described earlier, fear of ambiguity pertains to the difficulties learners experience with respect to language forms, understanding what the speaker is saying, or producing responses in communicative situations. As Dewaele and Ip (2013) indicate, "everything in a new FL (foreign language) is potentially ambiguous, which can also contribute to the sense of challenge to learners" (p. 61). Specifically in the Turkish context, as suggested by Thompson and Aslan (2015), the existence of fear of ambiguity may be attributed to the 
typical "teacher-fronted" and "grammar-focused" nature of the learning environment, which Alptekin and Tatar (2011) note as the prevailing trend in the Turkish EFL context. Indeed, it is challenging to integrate communicative language teaching into predominantly teacher-centred contexts where students memorize vocabulary, practice grammar drills and read aloud texts with limited opportunities to negotiate meaning. As the present study shows, learners' beliefs about fear of ambiguity (BALLIF4) are significantly positively correlated with English class performance anxiety $(r=.54)$. This finding resonates with the significant positive correlation found in Mori (1999) between the epistemological belief "simple knowledge" and language learning belief "avoid ambiguity" $(r=.45)$, which suggests that learners who believe that knowledge in general must have a simple structure tend to seek unambiguous and clear-cut linguistic forms when learning a foreign language. By the same token, as the present study demonstrates, the more learners believe that language learning is a task that involves a lot of ambiguity in various forms, the more anxious they will likely get as they perform in the language class. To this end, as Thompson \& Khawaja (2015) suggest, awareness-raising activities can be created in order to lower learners' anxiety in the classroom. Grammar activities, for instance, can be created in ways in which learners first attend to meaning rather than form. For instance, a learner may utter a sentence in which the verb tense is incorrect (i.e. the form) but meaning can still conveyed and understood via a lexical item (e.g., Yesterday I watch the documentary.). In a situation like this, focusing on the verb tense and correcting the error on the spot may provoke that learner's speaking anxiety because the correction might suggest that the original utterance was not the communicative. Mistakes pertaining to irregular language forms (e.g., irregular past tense verbs) and other errors may be corrected via different feedback types (see Lyster and Ranta, 1997) by providing learners with opportunities to draw on their own linguistic repertoire, knowledge and skills. 2 As suggested by Ely (1995), learners' tolerance of ambiguity can be regulated by teachers through linguistic research or problem-solving activities, thereby learners see linguistic differences as an 
opportunity to explore and not something to feel anxious about. Additionally, the idea that being able to understand every word that is heard or read or using forms accurately at all times is not crucial for language learning can be reinforced in order to reduce learners' fear of ambiguity in the classroom. As Gregersen and Horwitz (2002) argue, perfectionist students who wish to speak accurately and easily like native speakers, without grammatical or phonological errors, need to understand that the classroom is a place to learn and gain skills and that errors are a natural part of everyone's language learning experience. In this vein, , teachers need to emphasize in language classes that linguistic accuracy is not always the necessary precursor for conveying meaning, as meaning can still be negotiated and understood, despite the grammatical inaccuracies. Indeed, second language acquisition research shows that learners try to get meaning from input before they process the forms in the input. This means they may not notice and process the underlying grammatical structure that governs the way the words are ordered but still can get the gist of the message conveyed (VanPatten, 2004).

The significant positive correlation between FLCAS-F2 (confidence with English) and BALLIF3 (confidence in English and desire to interact with native speakers and culture) $(r=.42)$ suggests that confidence in English is associated with favorable attitudes and beliefs about English-speaking people and cultures. This finding is partly in line with the factor identified in Öz (2007) "beliefs about social interaction and learning spoken English" because this study found that female learners hold stronger beliefs about not only social interaction and learning spoken English but also foreign language aptitude. Additionally, it was found that females tend to enjoy studying English and talking to native speakers and consider vocabulary and pronunciation more important. On the contrary, the present study revealed an interesting correlation between BALLI-F3 and FLCAS-F3 (negative feelings towards English) $(r=.35)$. What this moderate correlation suggests is that when learners have stronger beliefs about interacting with native speakers and cultures, they actually report negative feelings towards English in the classroom setting. This interesting finding suggests that there is a mismatch 
between learners' experiences with learning English in the classroom and their confidence in English and desire to interact with native English speakers. In other words, learners may not find the foreign language classroom experience as authentic and fun as it would be when they actually interact with English speakers in realistic situations outside the classroom setting. For instance, a learner may not enjoy doing a role-play activity in the classroom where he or she needs to order food in a restaurant. However, when the same learner engages in the same communicative act in an authentic environment, he or she might perceive it as a more successful accomplishment. Therefore, the foreign language classrooms must include more authentic communicative activities rather than formal grammar and vocabulary activities where learners simply fill in the blanks or complete multiple choice tests. Additionally, learners must be encouraged to do activities outside the instructional setting, such as interviewing native speakers, other learners, or language teachers. These kinds of activities can make language learning more meaningful and purposeful, and learners can develop more favorable attitudes towards language instruction in formal learning settings. Although it seems plausible that confidence in English can encourage learners to interact with native speakers of the target language, there might be other variables, such as gender, that might account for learner beliefs and anxiety levels. Therefore, future research is needed to investigate the impact of different variables such as gender, personality, and context of learning on language learners' beliefs and anxiety levels.

The present study is not one without limitations. First of all, although the present study revealed significant correlations between various language learning beliefs and anxiety, the strength of these correlations ranged from small to moderate. This means that there are additional factors or variables that account for the remaining variance. Additionally, although exploring relationships provides us important insights about learner beliefs and anxiety, the findings of this study does not allow us to establish causal claims about the relationships. For example, the existence of a relationship between fear of ambiguity and classroom performance anxiety does not allow us to conclude that fear 
of ambiguity causes anxiety. Secondly, this study does not establish links between learner beliefs and anxiety and different levels of language performance or achievement. Future research is needed to explore how the different constructs of beliefs and anxiety influence linguistic achievements of learners with respect to different skills such as listening, reading, writing, and speaking. Third, the data of the present study relies on self-report data that reflect learners' beliefs about language learning and anxiety levels at the time of data collection. In order to see dynamic changes in learner beliefs and anxiety profiles, studies with longitudinal designs in which learner beliefs are measured at different intervals must be conducted. Finally, the findings of the present study are limited to the Turkish EFL context and therefore the generalizability of the findings is also limited by this particular study population. More specifically, the sample population in this study consisted of Turkish EFL learners at the university level. This study can be replicated in other EFL and ESL settings for comparison and generalizability. Since language learner beliefs and foreign language anxiety are closely associated with cultural constructs, investigating particular cultural and educational contexts (the Turkish EFL context, in this case) can enable us to better understand specific learner groups (Turkish EFL students) and compare and contrast different groups. Specifically, in international educational contexts (e.g, intensive ESL programs in the US or UK) where Turkish students are present, the findings of this research would be helpful for educators and curriculum developers.

In conclusion, this study fills an important gap in the second/foreign language learning and teaching research. As previously reported and discussed, significant correlations were found between the underlying constructs of learner beliefs and foreign language anxiety. The findings of this study demonstrate that learner beliefs and anxiety in second/foreign language learning are not independent constructs. On the contrary, they interact with one another in complex ways, and the relationships between them enhances our understanding of second language acquisition and teaching. Therefore, it is 
hoped that the contribution of the present study will serve as a motivation for others to explore the relationships between other individual differences.

\section{References}

Alptekin, C., and Tatar, S. 2011. "Research on foreign language teaching and learning in Turkey (2005-2009)". Language Teaching, 44, 328-353. doi: 10.1017/S026144481100005X

Aida, Y. 1994. "Examination of Horwitz, Horwitz, and Cope's construct of foreign language anxiety: The case of students of Japanese.” Modern Language Journal 78 (2): 155-168. doi:10.1111/j.1540-4781.1994.tb02026.x

Ariogul, S., Dalim C. U., and Onursal, I. 2009. "Foreign language learners' beliefs about language learning: A study on Turkish university students." Procedia - Social and Behavioral Sciences 1(1): 500-1506. doi:10.1016/j.sbspro.2009.01.265

Cheng, Y.-S. 2001. "Learners' beliefs and second language anxiety.” Concentric: Studies in English Literature and Linguistics 27 (2): 209-223. Retrieved from http://www.concentriclinguistics.url.tw/ch/upload/articlesfs91402102553135620.pdf

Dewaele, J. M., and Ip, T. S. 2013. "The link between foreign language classroom anxiety, second language tolerance of ambiguity and self-rated English proficiency among Chinese learners." Studies in Second Language Learning and Teaching, 3(1): 47-66. Retrieved from http://eprints.bbk.ac.uk/8054/1/DewaeleShanIp2013.pdf

Diab, R. L. 2006. “University students' beliefs about learning English and French in Lebanon.” System, 34(1), 80-96. doi:10.1016/j.system.2005.06.014

Dörnyei, Z. 2005. The psychology of the language learner: Individual differences in second language acquisition. Mahwah, NJ: Erlbaum.

Dörnyei, Z. 2009. “The L2 motivational self-system.” In Motivation, language identity and the L2 self, edited by Z. Dörnyei \& E. Ushioda, 9-42. Clevedon: Multilingual Matters. 
Ellis, R. 2008. "Learner beliefs and language learning." In Innovation and tradition in ELT in the new millennium, edited by P. Robertson, R. Nunn, and D. Lingley, 7-25. Busan: Asian EFL Journal Press.

Ely, C. 1995. "Tolerance of ambiguity and the teaching of ESL." In Learning styles in the ESL/EFL classroom, edited by J. M. Reid, 216-217. New York: Heinle \& Heinle.

Furnham, A. 1994. “A content, correlational and factoranalytic study of 4 Tolerance of Ambiguity questionnaires.” Personality and Individual Differences, 16: 403-410. doi: 10.1016/01918869(94)90066-3

Furnham, A., and Ribchester, T. 1995. "Tolerance of ambiguity: A review of the concept, its measurement and applications.” Current Psychology 14 (3): 179-199. doi: 10.1007/BF02686907.

Gregersen, T., \& Horwitz, E. K. (2002). Language learning and perfectionism: Anxious and nonanxious language learners' reactions to their own oral performance. The Modern Language Journal, 86(4), 562-570. doi: 10.1111/1540-4781.00161

Horwitz, E. K. 1986. "Preliminary evidence for the reliability and validity of a foreign language anxiety scale." TESOL Quarterly, 20 (3): 559-562. doi: 10.2307/3586302

Horwitz, E. K., Horwitz, M. B., \& Cope, J. 1986. "Foreign language classroom anxiety.” Modern Language Journal, 70 (2): 125-132. doi:10.1111/j.1540 4781.1986.tb05256.x.

Horwitz, E. K. 1987. “Surveying student beliefs about language learning.” In Learner strategies in language learning, edited by A. L. Wenden, and Joan Rubin, 119-129. London: Prentice-Hall.

Horwitz, E. K. 1988. “The beliefs about language learning of beginning university foreign language students.” Modern Language Journal, 72 (3): 283-294. doi:10.1111/j.15404781.1988.tb04190.x 
Horwitz, E. K. 1995. "Student affective reactions and the teaching and learning of foreign languages." International Journal of Educational Research, 23 (7): 573-579. doi: 10.1016/08830355(96)80437-X

Kern, R. G. 1995. “Students' and teachers' beliefs about language learning.” Foreign Language Annals, 28 (1): 71-92. doi:10.1111/j.1944-9720.1995.tb00770.x

Loewen, S., Li, S., Fei F., Thompson, A., Nakatsukasa, K., Ahn, S., and Chen, X. 2009. “L2 learners' beliefs about grammar instruction and error correction.” Modern Language Journal, 93 (1): 91104. doi:10.1111/j.1540-4781.2009.00830.x

Lyster, R. \& Ranta, L. (1997). Corrective feedback and learner uptake: Negotiation of form in communicative classrooms. Studies in Second Language Acquisition, 20, 37-66.

Mori, Y. (1999). "Epistemological beliefs and language learning beliefs: What do language learners believe about their learning?” Language Learning, 49 (3): 377-415. doi:10.1111/00238333.00094

Nikitina, L., and Furuoka, F. 2007. "Beliefs about language learning: A comparison between novice and intermediate level students learning Russian at a Malaysian university.” In The Linguistics Journal, edited by P. Robertson and J. Adamson, 7-27. Road Town: Linguistics Press Journal http://www.linguisticsjournal.com/April_2007_ln\&ff.php

Okay, A., and Balcikanli, C. (2017). "Belief Patterns and Anxiety Levels of Turkish EFL Students In Relation To Level of Instruction.” i-Manager's Journal on Educational Psychology, 11 (2): 1828. Retrieved from https://search.proquest.com/openview/70f33c63bbb49d990c543cca8452fd60/1?pqorigsite $=$ gscholar $\& \mathrm{cbl}=2030629$

Oxford, R., and Ehrman, M. 1992. "Second language research on individual differences.” Annual Review of Applied Linguistics, 13: 188-205. doi: 10.1017/S0267190500002464 
Öz, H. 2007. "Understanding metacognitive knowledge of Turkish EFL students in secondary education." Novitas-ROYAL, 1 (2): 53-83. Retrieved from http://files.eric.ed.gov/fulltext/ ED501934.pdf

Thompson, A. S. 2013. "The Interface of Language Aptitude and Multilingualism: Reconsidering the Bilingual/Multilingual Dichotomy.” Modern Language Journal, 97: 685-701. doi:10.1111/j.1540-4781.2013.12034.x.

Thompson, A. S., and J. Lee. 2013. “Anxiety and EFL: Does Multilingualism Matter?” International Journal of Bilingual Education and Bilingualism 16: 730-749. doi:10.1080/13670050.2012.713322.

Thompson, A. S., and Aslan, E. 2015. "Multilingualism, perceived positive language interaction (PPLI), and learner beliefs: what do Turkish students believe?" International Journal of Multilingualism, 12 (3): 259-275. doi: 10.1080/14790718.2014.973413

Thompson A. S. and Khawaja, A. J. 2015. "Foreign language anxiety in Turkey: the role of multilingualism." Journal of Multilingual and Multicultural Development, 37 (2): 115-130. doi: $10.1080 / 01434632.2015 .1031136$

VanPatten, B. (2004). Input processing in SLA. In B. VanPatten (Ed.) Processing instruction: theory, research, and commentary (pp.5-31) Mahwah, NJ: Erlbaum.

Young, D. J. 1991. "Creating a low-anxiety classroom environment: What does language anxiety research suggest?" Modern Language Journal, 75 (4): 426-439. doi: 10.1111/j.15404781.1991.tb05378.x 